\title{
TRANSFORMAÇÃO DA ECONOMIA DIRECIONADA AO CRESCIMENTO E AO ALCANCE DO PROGRESSO SOCIAL, SOB A ÉGIDE DA CONSTITUIÇÃO FEDERAL DE 1988
}

\author{
TRANSFORMATION OF ECONOMY DIRECTED TO \\ GROWTH AND SOCIAL PROGRESS FROM THE \\ PERSPECTIVE OF THE 1988 FEDERAL CONSTITUTION
}

\section{Dinaura Godinho Pimentel Gomes"}

\begin{abstract}
Resumo: $\mathrm{O}$ presente artigo versa sobre a necessidade da atuação positiva do Estado Democrático de Direito, com seriedade e transparência, na ordem econômica e social, eis que, no exercício pleno de sua soberania, tem como estabelecer eficazes políticas públicas e aplicar investimentos de qualidade no intuito prospectivo de construir uma sociedade livre, justa e solidária; garantir o desenvolvimento nacional; erradicar a pobreza e a marginalização, reduzindo as desigualdades sociais, além de promover o bem de todos, como impõe o art. 3o, inciso III, da Constituição Federal. Assim, nos limites dos princípios e regras constitucionais, deve intervir, cada vez mais, nas relações jurídicas, de tal modo que as transformações estruturais da economia tenham por objetivo alcançar, por primeiro, o progresso social da Nação como finalidade própria do desenvolvimento que tanto se almeja. Com isso, deve fazer valer os direitos fundamentais de cada cidadão, principalmente através do trabalho, enquanto meio preponderante para assegurar o direito à vida com dignidade.
\end{abstract}

Palavras-chave: Transcendência do princípio fundamental da dignidade humana. Transformação da economia na era da informação. Valorização do trabalho humano a partir da efetiva garantia do acesso ao trabalho.

Abstract: The present article is about the necessity of positive action of the Democratic Constitutional State, with dignity and transparency, in the economical and social orders, as, in its ample exercise of sovereignty, the State has the means to establish effective public policies and invest qualitatively in the intent to prospectively build up a free, just and solidary society; guarantee national development; eradicate poverty and marginalization, diminishing social differences as well as promoting the well-being of all, as art 3o, incision III of the Federal Constitution enforces. Therefore, to the limits of principles and constitutional rules, it should intervene to an ever increasing degree in the legal relations in such a way that the structural transformations of the economy focus primarily on the social progress of the nation as the very end of the so

"Doutora em Direito do Trabalho e Sindical pela Universidade Degli Studi di Roma La Sapienza, com revalidação pela Universidade de São Paulo - USP. Pós-doutora em Direito junto à Pontifícia Universidade Católica - PUC-SP. Juíza do Trabalho Titular da $1^{\circ}$ Vara de Londrina - Paraná. Professora Universitária. Email: sergiodinaura@ sercomtel.com.br 
much desired development. Thus, it should validate the fundamental rights of each citizen, mainly through labor as a predominant means of assuring the right to life with dignity.

Key-words: Transcendence of the fundamental principle of human dignity. Transformation of economy in the information era. Valorization of labor through the actual guarantee of access to work.

\section{INTRODUÇÃO}

Em face da recente crise financeira provocada pelos Estados Unidos com sérias repercussões na Europa, China, Japão e nos países da América Latina, dentre os quais o Brasil, já se admite, sem qualquer perplexidade, ser indispensável a ação intervencionista governamental, no âmbito da política econômica, inclusive por aqueles seguidores da ideologia neoliberal, do "laissezfaire”, a qual se mostrava forte e dominante há mais de três décadas.

Assim, a realidade hodierna aponta a manifesta incapacidade do livre mercado de resolver sua própria crise financeira e, mais ainda, os problemas sociais. Com isso, exige-se a atuação positiva, séria e transparente do Estado, voltada à promoção, incentivo, planejamento e à implantação de sérias políticas públicas, destinadas a conduzir a ordem econômica em busca do equilíbrio financeiro e do progresso social.

Nessa senda, torna-se indispensável ressaltar a supremacia da Constituição Federal, no ordenamento jurídico brasileiro, de forma a realizar seus valores e real sentido em prol de uma sociedade mais humana e mais justa, a partir da valorização do trabalho humano.

Com efeito, sem trabalho humano - e sem emprego - não há possibilidade de se almejar o crescimento de uma sociedade capitalista por ser o principal meio de se assegurar à maioria dos cidadãos ativos o direito à vida com dignidade.

É imperioso, portanto, seguir sempre em busca de uma interação expansionista dos valores da liberdade e da igualdade, centrados no postulado da dignidade humana, no campo econômico e social, em prol da efetiva realização do valor "justiça”, como fundamentos do Estado Democrático de Direito. É o que a Lei Maior estabelece. O que falta, muitas vezes, é a vontade de Constituição (HESSE, 1991, p. 19).

\section{UM PERFIL JURÍDICO-FILOSÓFICO DO VALOR DIGNIDADE}

A dignidade humana traduz uma especificação material e independente de qualquer tempo e espaço. Consiste em considerar que cada pessoa possui um 
espírito impessoal, o que a torna capaz de tomar suas próprias decisões a respeito de si mesma e de tudo que gira ao seu redor. Detém o peculiar poder de se autodeterminar, orientando sua liberdade pela razão à semelhança de Deus. Por tudo isso, é preciso considerar que "a dignidade humana consiste na eminência ou excelência do ser humano, mediante uma intensa participação no mais alto grau do ser, que o constitui um ser dotado de debitude e exigibilidade em relação a si mesmo e em relação aos demais homens. Em outras palavras, tratase de um ente cuja ordem do ser compreende a ordem do dever ser" (JAVIER HERVADA, 2008, p. 311). Assim, a dignidade reside na natureza racional ou espiritual do homem, como imagem do Deus Criador.

No contexto da evolução histórico-filosófica da ciência jurídica, o pensamento de KANT apresenta-se como o mais expressivo, no que concerne à conceituação da dignidade da pessoa humana como fim e não como meio. Serve para robustecer a linha do pensamento voltada contra qualquer tendência à coisificação ou instrumentalização do ser humano (SARLET, 2001, p. 35), jungida à exigência por ele enunciada como segunda fórmula do imperativo categórico.

Vale dizer, indiscutivelmente, a assertiva de Kant (1980, p. 135, grifo nosso) de que "o homem, e duma maneira geral, todo o ser racional, existe como um fim em mesmo, não só como meio para o uso arbitrário desta ou daquela vontade" ${ }^{1}$, é mais do que oportuna para os dias de hoje, principalmente no mundo do trabalho, para chamar à reflexão para o valor da pessoa humana como ser social, como valor-fonte de todos os valores, na hodierna e feliz expressão do jusfilósofo brasileiro Miguel Reale (1988, p. 159). Resulta daí que o outro deve ser compreendido não como mero objeto, porém reconhecido como sujeito, tratado como fim em si mesmo, de onde se vislumbra não somente a dimensão individual da pessoa humana, mas também sua dimensão comunitária e social.

\footnotetext{
${ }^{1}$ A propósito, Nicola Abbagnano (1962, p. 259) assim bem explica o pensamento de Kant: "Age de forma que trates a humanidade, tanto na tua pessoa como na pessoa de qualquer outro, sempre também como um fim e nunca unicamente como meio". Esse imperativo estabelece na verdade que todo homem, aliás, todo ser racional, como fim em si mesmo, possui um valor não relativo (como é, por ex., um preço), mas intrínseco, isto é, a dignidade. Para Kant, "o que tem um preço pode ser substituído por alguma coisa equivalente; o que é superior a todo preço e, portanto, não permite nenhuma equivalência, tem uma dignidade". Substancialmente, a dignidade de um ser racional consiste no fato de que ela "não obedece a nenhuma lei que não seja instituída por ele mesmo". A moralidade, como condição dessa autonomia legislativa, é, portanto, a condição da dignidade do homem e moralidade e humanidade são as únicas coisas que não têm preço...
} 
É nesse sentido que foram desenvolvidas as linhas do pensamento filosófico contemporâneo, no sentido de enfrentar o positivismo jurídico e o ceticismo moral, ao final materializadas em textos constitucionais, que incorporaram esses princípios éticos com os quais as regras jurídicas e as decisões judiciais devem ser compatíveis. No entanto, tal reconhecimento institucional é muito recente, surgindo após a era Hitler marcada pelos horrores do Nazismo, quando houve o envio aos campos de concentração de 18 milhões de pessoas, causando a morte de 11 milhões, das quais 6 milhões de judeus. Todas essas pessoas foram desconsideradas, pelo próprio Estado, em sua essência e dignidade, apenas por não pertencerem à escolhida raça ariana ou pelo fato de não serem enquadradas nos padrões de sociedade rigidamente preestabelecidos, como os ciganos e os homossexuais.

A partir desse extermínio brutal, lembrado e abominado constantemente até os dias de hoje, buscou-se a imediata e efetiva reconstrução dos direitos humanos, espelhada na Declaração Universal dos Direitos Humanos (adotada e proclamada pela Resolução n. 217 A (III) da Assembléia Geral das Nações Unidas, em 10 de dezembro de 1948, assinada pelo Brasil na mesma data. Para tanto, com essa Declaração, foi introduzida a revisão da noção tradicional da soberania absoluta do Estado-nação, ao se reconhecer, no âmbito global, a "dignidade inerente a todos os membros da família humana".

Dito de modo diferente, desde então, toda pessoa humana passou a ser vista como sujeito de direito internacional, cuja tutela não se restringe mais à competência nacional ou à jurisdição doméstica exclusiva. A respeito, eis o que reza o art. 22, da citada Declaração:

Toda pessoa como membro da sociedade tem direito à segurança social e à realização, pelo esforço nacional, pela cooperação internacional e de acordo com a organização e recursos de cada Estado, dos direitos econômicos, sociais e culturais indispensáveis à sua dignidade e ao livre desenvolvimento de personalidade (grifo nosso).

Exsurge então o primeiro passo de reconstrução universal da sociedade e do Estado em prol do bem de todas as pessoas, sem qualquer distinção, tendo como núcleo central o respeito à dignidade da pessoa humana, a exemplo do que dispôs a Lei Fundamental da República Federal da Alemanha, de 23 de maio de 1949, que, por primeiro, erigiu a dignidade da pessoa humana em direito fundamental, ao proclamar, no seu art. $1^{\circ}$, o seguinte:

(1) A dignidade da pessoa humana é inviolável. Todas as autoridades públicas têm o dever de a respeitar e a proteger.

(2) O Povo Alemão reconhece, por isso, os direitos invioláveis e inalienáveis da pessoa humana como fundamento de qualquer comunidade humana, da paz e 
da justiça no mundo [...]. (A LEI..., 1996, p. 124).

Um pouco antes, a Constituição da República Italiana, de 27 de dezembro de 1947 , em seu art. $3^{\circ}$, passou a declarar expressamente que todos os cidadãos têm igual dignidade social, sem qualquer distinção, e estabelece o seguinte:

ART. 3. Tutti i cittadini hanno pari dignità sociale e sono eguali davanti alla legge, senza distinzione di sesso, di razza, di lingua, di religione, di opinioni politiche, di condizioni personali e sociali.

Ė compito della Repubblica rimuovere gli ostacoli di ordine economico e sociale, che, limitando di fatto la libertà e l'eguaglianza dei cittadini, impediscono il pie no sviluppo della persona umana e l'effettiva partecipa zione di tutti i lavoratori all' organizzazione politica, economica e sociale del Paese. ${ }^{2}$

Cumpre destacar, também, que essa Constituição, em seu art. $1^{\circ}$, proclama que "a Itália é uma República democrática fundada no trabalho"3.

Bem posteriormente, a Constituição da República Portuguesa, aprovada em 2 de abril de 1976, em seu art. $1^{\circ}$, assim veio a proclamar de forma incisiva:

"Portugal é uma República soberana, baseada na dignidade da pessoa humana e na vontade popular e empenhada na construção de uma sociedade livre, justa e solidária”.

É o que se deu também com a Constituição Espanhola, de 29 de dezembro de 1978, ao estatuir, em seu art. 10, que a dignidade da pessoa e os direitos fundamentais que the são inerentes, dentre outros valores voltados ao livre desenvolvimento da personalidade, são fundamentos da ordem política e da paz social, nos termos seguintes:

Art. 10

1. La dignidad de la persona, los derechos inviolables que le son inherentes, el libre desarrolo de la personalidad, el respeto a la ley y a los derechos de los demás son fundamento del orden político y de la paz social [...].

Espelhada mais especificamente nas Constituições portuguesa e espanhola, a vigente Constituição Federal brasileira, promulgada em 05 de outubro de 1988, também se inspirou nos cânones democráticos do século XX, ao se voltar enfaticamente para a plena realização da cidadania, elegendo o valor da dignidade humana como um dos fundamentos do regime político democrático que instaurou e institucionalizou (art. 1ํㅜㅇ inc. III). Para tanto, proclama a

2 "É tarefa da República remover os obstáculos de ordem econômica e social que, limitando de fato a liberdade e a igualdade dos cidadãos, impedem o pleno desenvolvimento da pessoa humana e a efetiva participação de todos os trabalhadores na organização política, econômica e social do País” (tradução livre da autora).

${ }^{3}$ Principi fondamentali - 1. L'Italia è una Repubblica democratica, fondada sul lavoro... (tradução livre). 
prevalência dos direitos humanos (art. 4을 inc. II) e a exeqüibilidade plena dos direitos fundamentais (em seu preâmbulo), alargando sua dimensão para alcançar os direitos fundamentais sociais (arts. $6^{\circ}, 7^{\circ}$ e $8^{\circ}$ ). Assim, estabelece que a livre iniciativa não pode estar dissociada do princípio da dignidade humana, ao qual se reporta como princípio supremo da ordem constitucional e fim último da ordem econômica (art. $1^{\circ}$, inc. III c/c art. 170).

Sob tais enfoques, o Estado Democrático de Direito tem sido visto como o principal agente de processos de transformação, "comprometido com os valores da Democracia, entre os quais, o valor maior é o da dignidade da pessoa humana. É em respeito a este que os demais valores - vida, liberdade, igualdade, segurança, justiça, propriedade, desenvolvimento [...] - devem ser assegurados. Sem o reconhecimento da dignidade presente em todo ser humano, os demais valores ficam sem uma referência que lhes possibilite produzir sentido coerente com a idéia de Democracia [...]" nas precisas palavras de Sergio Alves Gomes (2008, p. 284).

\section{$2 \mathrm{O}$ FORTALECIMENTO DOS DIREITOS SOCIAIS VOLTADO AO DESENVOLVIMENTO ECONÔMICO: A EXPERIÊNCIA DO WELFARE STATE DURANTE OS ANOS DOURADOS}

No pós-guerra, tendo como núcleo central fortalecer a credibilidade nas instituições através do respeito à dignidade da pessoa humana, a atuação governamental dos países avançados, principalmente da Europa Ocidental, buscou jungir os objetivos de desenvolvimento econômico ao alcance da justiça social, tão destroçada, de modo a expandir um capitalismo includente, mediante a redução de desigualdades, tudo voltado à melhoria das condições de vida.

Vale dizer, essa nova era marcou a efetiva combinação do discurso liberal da cidadania com o discurso social, dando ênfase aos direitos sociais. Coube a cada governo do Estado-nação não apenas buscar a reconstrução da Europa, mas, também, garantir a justiça social, de modo a compensar e remover, de fato e de direito, as distorções causadas pelo livre mercado, que levaram à forte Depressão de 1929, e pelos malefícios de duas Grandes Guerras.

Dessa forte intervenção do Estado na ordem econômica e social, nos moldes defendidos por John Maynard Keynes, voltados a salvar o capitalismo, emergiram os denominados "anos dourados". Como relembra Eric Hobsbawm (2001, p. 262-3),

todos os problemas que perseguiam o capitalismo em sua era da catástrofe pareceram dissolver-se e desaparecer. O terrível e inevitável ciclo de prosperidade e depressão, tão fatal entre as guerras, tornou-se uma sucessão de brandas 
flutuações, graças a - eram o que pensavam os economistas keynesianos que agora assessoram os governos - sua inteligente administração macroeconômica. Desemprego em massa? Onde se poderia encontrá-lo no mundo desenvolvido da década de 1960, quando a Europa tinha uma média de 1,5\% de sua força de trabalho sem emprego e o Japão 1,3\%... Só na América do Norte ele ainda não fora eliminado... Naturalmente a maior parte da humanidade continuava pobre, mas nos velhos centros industrializados, que significado poderia ter o "De pé, ó vítimas da fome", da 'Internationale' para trabalhadores que esperavam possuir seu carro e passar as férias anuais remuneradas nas praias da Espanha? E se os tempos se tornassem difíceis para eles, não haveria um Estado previdenciário universal e generoso pronto para oferecer-lhes proteção, antes nem sonhada, contra os azares da doença, da desgraça e mesmo da terrível velhice dos pobres? Suas rendas cresciam ano a ano, quase automaticamente. [...].

Com essa expansão gerada pelo Estado do Bem-Estar Social, houve mais estabilidade e mais segurança, tanto no emprego, mediante o sistema público de emprego, quanto nas políticas públicas de seguridade social. Nesse círculo virtuoso, com a expansão das responsabilidades do Estado, aumentando a capacidade de gastos públicos, geraram investimentos e consumo. $\mathrm{O}$ alto crescimento da produtividade propiciou o crescimento do salário dos trabalhadores, praticamente em todos os níveis. Bem a propósito, Marcelo W. Proni (2006, p. 3) destaca que,

nas principais nações capitalistas, no pós-guerra, os governos foram levados a assumir medidas que ultrapassavam a tarefa de resguardar a economia nacional da racionalidade especulativa dos mercados financeiros, assim como de proteger a população contra os desastres econômicos. Compreendeu-se a importância de restaurar a confiança nas instituições, de gerar expectativas corretas em relação ao desempenho da economia e de cultivar um clima de otimismo em relação ao futuro. Mas, acima de tudo, as novas estratégias de concorrência, o novo cenário político e as novas demandas sociais redefiniram o papel do Estado e ampliaram em muito as responsabilidades das autoridades governamentais.

A fim de promover a justiça social, a ação governamental do Estado passou a desenvolver a tarefa de coordenação e colaboração no âmbito de uma ordem capitalista comprometida com objetivos de cunho social. Ao abandonar sua aparente neutralidade, típica do Liberalismo, o Estado social ${ }^{4}$ tomou efetivas

${ }^{4}$ Com muita propriedade, o Prof. Marcelo W. Proni também ensina que "os anos dourados foram marcados por relações comerciais e financeiras bastante dinâmicas e por uma relativa estabilidade do padrão monetário internacional (baseado na paridade entre o dólar e o ouro)... Com o tempo, um conjunto de políticas públicas destinadas à seguridade e à promoção social (em especial as políticas nas áreas de educação, saúde, habitação, transporte público, previdência e assistência social) foi capaz de satisfazer as necessidades básicas da população e superar a pobreza absoluta. Note-se que, dado o contexto político-ideológico da época, a prioridade inicial dos governantes foi afastar 
providências para a obtenção de um desenvolvimento econômico mais solidário e menos desigual, dando ênfase ao respeito da dignidade da pessoa humana.

Trata-se de aspectos tão positivos daquele reinante capitalismo social, que, hodiernamente, se apresentam em total sintonia com os fundamentos e finalidades traçados pelas Constituições modernas, que instituíram o Estado Democrático de Direito.

Nessa senda, ao tratar preceito constitucional estatuído no art. 1ํㅡㄹ da Lei Fundamental alemã, retro referido, como fundamento da comunidade estatal, Peter Häberle (2005, p. 128) pontua que,

uma Constituição que se compromete com a dignidade humana lança, com isso, os contornos da sua compreensão do Estado e do Direito e estabelece uma premissa antropológico-cultural. Respeito e proteção da dignidade como dever (jurídico) fundamental do Estado constitucional constitui premissa para todas as questôes jurídico-dogmáticas particulares. Dignidade humana constitui a norma fundamental do Estado, porém é mais do que isso: ela fundamenta também a sociedade constituída e eventualmente a ser constituída. Ela gera uma força protetiva pluridimensional, de acordo com a situação de perigo que ameaça os bens jurídicos de estatura constitucional.

Eis, aqui, a lição que se tira do fortalecimento do papel do Estado, buscando a reconstrução dos países destroçados pela guerra e o posterior progresso mediante a efetividade dos direitos sociais de um modo geral, nesses 'anos dourados', de 1945 a 1975. A vontade política, embasada na vontade de Constituição, pôde bem direcionar a transformação da sociedade em vista de um mundo mais humano, alicerçado em princípios democráticos a informarem o desenvolvimento econômico direcionado ao alcance do progresso social. Para tanto, pouco importou se as medidas adotadas tiveram em mira, por primeiro, assegurar a estabilidade das economias capitalistas, pois a característica maior do Estado social se manifestou pela explícita adesão à ordem capitalista, contudo, direcionada a resguardar a dignidade humana de todas as pessoas, o que refoge dos objetivos do próprio mercado.

Bem a propósito, Paulo Bonavides $(2001$, p. 184, 187) ensina que

"o Estado social representa efetivamente uma transformação superestrutural por que passou o antigo Estado liberal. Seus matizes são riquíssimos e diversos.

o pesadelo da Grande Depressão e não dar motivos para qualquer movimento substancial contra as instituições democráticas e os fundamentos do capitalismo. Houve, como se diz, um acordo tácito, que envolvia a concessão de direitos sociais, a regulamentação da economia de mercado, a manutenção do pleno emprego e a elevação do poder de compra dos salários em troca do reconhecimento da propriedade privada, da preservação da livre iniciativa, da promoção do crescimento econômico e do abrandamento da luta de classes. (PRONI, 2006, p. 15, 21, grifo nosso). 
Mas algo, no Ocidente, o distingue, desde as bases, do Estado proletário, que o socialismo intenta implantar: é que ele conserva sua adesão à ordem capitalista, princípio cardeal a que não renuncia. Daí compadecer-se o Estado social no capitalismo com os mais variados sistemas de organização política, cujo programa não importe modificações fundamentais de certos postulados econômicos e sociais [....]. O Estado social que temos em vista é o que se acha contido juridicamente no constitucionalismo democrático. Alcançá-lo já foi difícil; conservá-lo, parece quase impossível. E, no entanto, é o Estado a que damos, do ponto de vista doutrinário, valoração máxima e essencial, por afigurar-se-nos aquele que busca realmente, como Estado de coordenação e colaboração, amortecer a luta de classes e promover, entre os homens, a justiça social, a paz econômica.

Toda essa experiência que marcou a era dos 'Anos de Ouro' - e da plena florescência do Estado Social, do qual os brasileiros, lamentavelmente, não tiveram a oportunidade de vivenciar - deve ser trazida à reflexão para indicar caminhos mais definidos e decisões apropriadas à resolução dos problemas econômicos e sociais provocados pela atual (e de grandes proporções) crise financeira mundial, que vem exigindo gigantesca ação intervencionista e regulatória por parte do Estado, a exemplo da emergencial atuação de governos dos EUA, da Europa e China. Tudo de modo a garantir a economia de mercado.

Exsurge daí ser possível, sim, obter, nos dias de hoje, a transformação superestrutural das políticas estatais voltada a promover o desenvolvimento econômico jungido ao progresso social, que tanto se almeja e a Constituição Federal brasileira exige.

\section{A NECESSÁRIA VALORIZAÇÃO DO TRABALHO HUMANO COMO FUNDAMENTO DA PRÓPRIA DEMOCRACIA}

Conforme já demonstrado, o postulado da dignidade humana passou a ser o epicentro do grande elenco de direitos civis, políticos, econômicos culturais e sociais, inter-relacionados e interdependentes numa abordagem holística, tal como vem proclamado não só pelas constituições de cada Estado-nação de cunho democrático, mas principalmente através de Tratados Internacionais de Direitos Humanos. Tornou-se, assim, o elemento referencial para a aplicação e interpretação das normas jurídicas, de modo a exigir uma concepção diferenciada do que seja segurança, igualdade, justiça e liberdade, para impedir que o ser humano institucionalmente seja novamente tratado como mero objeto.

Como o tema da dignidade humana não é estático na ordem democrática, as normas constitucionais não podem ser consideradas de forma isolada e dispersa, mas, sim, como preceitos integrados num sistema unitário de regras e princípios (CANOTILHO, 1992, p. 232). 
Vale dizer, a Constituição é posta não apenas como limite, mas sobretudo como fundamento da ordem jurídica, justamente para garantir a igualdade substancial, ao proclamar a dignidade da pessoa humana como fundamento do Estado Democrático de Direito e um valor que atrai a realização dos direitos fundamentais do homem, em todas as suas dimensões. É por isso que a democracia tem sido considerada como "o único regime político capaz de propiciar a efetividade desses direitos” (SILVA, 1998, p. 93).

Entretanto, mesmo diante de dessas conquistas que renderam uma formidável previsão de normas internacionais de proteção dos direitos humanos, princípios e regras constitucionais, normas legais e coletivas, no âmbito de um Estado Democrático de Direito, o Ser Humano ainda não se posicionou em sintonia com a aspiração de uma sociedade justa, dependente de um equilíbrio estável e de uma harmonia duradoura. Persiste, hodiernamente, a forte tendência de predominância do capitalismo perverso que aniquila o valor do trabalho humano e, por conseqüência, afronta a dignidade de cada trabalhador.

Isto porque, diante da expansão do neoliberalismo, o Estado-nação passou a ser visto tendencialmente minimizado no que tange ao desenvolvimento e expansão das políticas públicas, em defesa da concretização dos direitos sociais. Sobressaem polêmicas posições da maioria dos grandes e poderosos conglomerados transnacionais, a impor programas de privatização dos monopólios públicos e a substituição dos mecanismos estatais de seguridade social por seguros privados, o que amplia sobremaneira o pluralismo de ordens normativas. A respeito dessa transformação, imposta nesses moldes, com fortes e negativos reflexos no mundo do trabalho assim prelecionam José Ricardo Ramalho e Marco Aurélio Santana (2003, p. 12-13):

O mundo do trabalho, principalmente em países desenvolvidos, se modificou rapidamente e o consenso protetor do welfare state foi substituído pela dieta neoliberal. Muitas certezas, consolidadas há pelo menos cinqüenta anos, em termos da importância do papel do Estado na economia e da necessidade de processos regulatórios para manter a proteção social, foram profundamente abaladas ou enfraquecidas no debate público. Não tardou para que a experiência dos países centrais transbordasse, alcançando também os países periféricos, onde tanto a proteção social como a formalização das relações de trabalho já não eram das mais sólidas [...].

Formas de contratação flexíveis, antes consideradas atípicas, passaram a ser a regra. As políticas de proteção ao indivíduo, dentro e fora do trabalho, foram sendo substituídas por políticas de aumento de competitividade. A própria avaliação acerca da desigualdade social mudou de perspectiva. Pensada antes, na ótica do Estado de bem-estar, como problema a ser tratado com o aumento dos benefícios sociais, passava, sob a nova ótica do Estado mínimo, a ser identificada como necessária para o maior engajamento e desempenho dos indivíduos na sociedade [...]. 
Os fenômenos sociais que temos presenciado não são de fácil encaixe nas categorias preexistentes. Tratar-se-ia, portanto, de uma nova questão social. O trabalho, um dos eixos centrais de vertebração da ordem social moderna, ficou enfraquecida, com a chamada crise do trabalho, e a sociedade sofreu as conseqüências, através de problemas sociais diferenciados, no que já vem sendo designado como a nova era das desigualdades, marcada, entre outras características, pela perda de institutos de proteção social, pelo aumento das taxas de pobreza global e pelo aumento das disparidades sociais, enfim, pela ampliação das margens de vulnerabilidade social e econômica.

Advém dessa dura realidade o lado perverso e desagregador das políticas econômicas neoliberais que mais disseminam a desigualdade social, pois retiram o valor do trabalho humano, fazendo desencadear um crescimento profundo da divisão da sociedade ${ }^{5}$, que se torna incapaz de oferecer soluções aos problemas de desemprego, da desigualdade de renda ${ }^{6}$, da violência sexual e da miséria.

Ora, no seio de toda sociedade regida pelo Estado Democrático de Direito, o desenvolvimento deve ser relacionado a um processo de transformação voltado ao progresso. É considerado desenvolvido o país que não tem dependência tecnológica nem financeira, resultando daí mais estabilidade nas relações econômicas e sociais. No entanto, como bem acrescenta Ricardo Antunes (2005, p. 116),

essa nova conformação produtiva do capital desafia [...] crescentemente, o mundo do trabalho, uma vez que o centro da confrontação social contemporânea é dado pela contradição entre o capital social total e a totalidade do trabalho (MÉSŹ́ROS, 1995). Assim, como o capital utiliza-se desses mecanismos

${ }^{5}$ Simon Schwartzmn (2004, p. 178-9) ressalta que a desigualdade de renda no Brasil é considerada uma das mais altas do mundo. Assinala que, "estudos econométricos mostram que, dos diversos fatores que afetam a renda - região, idade, sexo, tipo de ocupação, educação, etc. -, o mais importante, de longe, é a educação. Em 2001, o rendimento mensal médio de quem tinha educação superior era cerca de $R \$ 2.200$ - um bom salário da classe média, mas longe de indicar riqueza - enquanto o rendimento médio de quem não tinha educação era 10 vezes menor. A implicação desse fato é que o caminho mais importante para melhor distribuição da renda é o aumento e a melhor distribuição das oportunidades educacionais e não a redistribuição da riqueza". E, ao tratar da pobreza, miséria e indigência, em seguida, enfatiza que "existem boas razões para se preocupar com as situações de pobreza extrema e desenvolver políticas assistenciais e compensatórias que possam socorrer as pessoas em situações de maior privação. Mas a prioridade deve estar em melhorar a qualificação e as oportunidades de trabalho e geração de renda das pessoas" (grifo nosso).

${ }^{6}$ Nesse sentido, Marcio Pochmann (2008, p. A3) conclui que "a aplicação das políticas econômicas e sociais neoliberais não se mostrou determinante para a expansão ou não das economias avançadas. Seus efeitos distributivos, contudo, não deixaram dúvidas sobre o seu caráter de aprofundamento da desigualdade, tendo em vista os prejuízos impostos aos mais pobres". A escolha dos países ricos e a desigualdade. 
mundializados e dispõe de seus organismos internacionais, a luta dos trabalhadores deve ser cada vez mais caracterizada pela sua configuração também internacionalizada. E, nesse terreno, como sabemos, a solidariedade e a ação de classe do capital está bem à frente da ação dos trabalhadores.

Emerge daí que o Estado-nação deve intervir cada vez mais nas relações jurídicas, para garantir a realização dos direitos fundamentais de cada cidadão, principalmente através do trabalho, enquanto meio preponderante para assegurar o direito à vida com dignidade. Se não há mercado sem o Estado, conforme vem se proclamando (SORMAN, 2008, p. B7), agora, com mais freqüência e ênfase diante da atual crise financeira internacional do século XXI, também não se pode pensar em desenvolvimento de uma sociedade capitalista sem a valorização do trabalho.

Urge, portanto, dar ao DIREITO um sentido de instrumento transformador dessa vigente realidade injusta. Advém dessa assertiva a necessidade de se afirmar de forma permanente a supremacia da Constituição Federal em prol da concretização dos direitos fundamentais sociais, centrada no respeito à dignidade humana. Para tanto, é preciso recolocar em prática esquemas de cooperação entre as funções estatais e as forças produtivas, inter-relacionando as potencialidades do mercado com as políticas públicas, em busca do desenvolvimento econômico e do progresso social do país. Constitui impostergável tarefa do Estado, estabelecer diretrizes para o exercício da atividade econômica tendentes à formalização de uma ordem futura mais justa, mais humana e mais fraterna (Preâmbulo da Lei Maior). Nessa senda, o art. 174, caput, da Constituição Federal, estabelece, como tarefa do Estado, o exercício das funções de "fiscalização, incentivo e planejamento, sendo este determinante para o setor público e indicativo para o setor privado."

Com efeito, a Constituição Federal brasileira estabelece regras e princípios objetivos da vida social, impondo até mesmo intervenções governamentais para remodelar as instituições públicas e privadas, de forma a fortalecer o discurso social da cidadania, o que implica na conformação recíproca de metas de ambos setores (CF, art, 174), em prol da realização dos direitos fundamentais. Trata-se de atividade planificadora e indispensável do Estado, justamente para possibilitar a igualdade de oportunidades, o mesmo ponto de partida para todos. Como detentor da soberania, deve resgatar e promover a participação ativa dos corpos intermediários da sociedade civil, cada vez mais pluralista, propondo, como meta primeira, o desenvolvimento eficaz do sistema educacional, a englobar a permanente capacitação para o trabalho, os programas de saúde pública e de seguridade social. 
Dessa interação certamente poderá resultar maior efetividade dos direitos individuais e coletivos, calcados no postulado da dignidade da pessoa humana. Isso porque apenas a ação estatal soberana tem como melhor concretizar a tutela constitucional porque alcança não só o indivíduo, mas também entidades de classe, organizações sindicais, blocos empresariais, grupos vulneráveis da sociedade civil, entre outros. Segundo Simon Schwartzman (2004, p. 186), as políticas de mobilização são aquelas que partem do princípio de que só através da participação e do envolvimento das comunidades afetadas é que políticas sociais podem ser efetivamente implementadas.

Argumenta ainda o festejado autor - ao salientar que, da oposição entre políticas universalistas e focalizadas, emerge muitas vezes o posicionamento daqueles que defendem o Estado do bem-estar social clássico e de outros que defendem a redução do setor público - que,

em um país como o Brasil, onde os gastos sociais são notoriamente mal direcionados e usados de forma ineficiente, a questão do papel do setor público ou do setor privado no provimento de serviços é mais genuína, no sentido de que incorpora, de fato, visões distintas sobre até onde pode ir o poder público na implementação de políticas sociais, e qual a possível participação do setor privado. Em algumas áreas, como a educação superior e o provimento de serviços de saúde, o setor privado tem presença dominante, e os problemas que se colocam têm a ver com a regulação dessas atividades, e não com sua legitimidade. Em outras áreas, como as da previdência social, energia, comunicações, transportes e outras, a capacidade financeira e técnica do setor público tem-se mostrado extremamente limitada, mas as experiências de privatização ainda não demonstraram, de forma inequívoca, sua pertinência.

De qualquer modo, é o Estado que deve agir, sempre e cada vez mais, sendo indispensável sua ação corretiva e regulatória ${ }^{7}$, traçando permanentes políticas públicas de fomento da economia, de modo a propiciar o crescimento do País nos seus diversos setores.

Dito de modo diferente, ao intervir com seriedade e transparência na ordem econômica e social, no exerć́cio pleno de sua soberania, o Estado tem como estabelecer eficazes políticas públicas sociais e aplicar investimentos de qualidade no intuito prospectivo de construir uma sociedade livre, justa e solidária; garantir o desenvolvimento nacional; erradicar a pobreza e a marginalização,

${ }^{7}$ Conforme defende Luiz Carlos Bresser-Pereira (2008, p. B2), ao sustentar que "existem boas razões para acreditarmos no desenvolvimento econômico e político dos povos. É absurda, porém, a ideologia que pretende alcançar o bem-estar econômico capitalista sem se beneficiar do desenvolvimento político democrático - sem contar com a ação corretiva e regulatória do Estado democrático e social que tão arduamente a sociedade moderna vem construindo e do qual faz parte um mercado livre mais regulado”. 
reduzindo as desigualdades sociais, além de promover o bem de todos, tal como impõe o art. $3^{\circ}$, inciso III, da Constituição Federal.

Eis, aqui, bem delineada, a função primordial do Estado Democrático de Direito. É para tanto que ele existe. Vale dizer, sua função precípua é assegurar igual dignidade para todos, indistintamente. E é através do trabalho, condignamente remunerado, aliado à efetividade de outros direitos sociais (CF, art. $\left.6^{\circ}\right)$, que se constrói uma sociedade democrática nesses moldes proclamados.

\section{A GARANTIA DO ACESSO AO TRABALHO E DA MANUTENÇÃO DO EMPREGO À LUZ DA LEI MAIOR}

A Constituição Federal de 1988 estabelece uma ordem econômica voltada a alcançar a justiça social. Desse modo, salvaguarda o capitalismo social ao dar prioridade ao valor do trabalho humano. Nos termos dos arts. $1^{\circ}$, incisos III e IV, 170, 193 e 219, inciso IV, a atividade econômica deve ser dinamizada, tendo em vista preservar a livre iniciativa e a livre concorrência, esta como caráter instrumental, porém tudo de modo a promover a existência digna de todos, partindo da valorização do trabalho humano. Este é o fim último da ordem econômica e social.

Bem a propósito, buscando dar uma conotação de equilíbrio para não ser elidida a livre iniciativa, Gastão Alves de Toledo ${ }^{8}$ (2004, p. 171) realça que

jogadas a si mesmas, as forças de produção podem caminhar num sentido inverso ao da justiça. Contudo, ainda assim, os Estados que mais têm avançado na melhoria da condição humana são justamente aqueles que adotam a liberdade de iniciativa. Ao Estado pode caber um papel redistribuidor da renda nacional e é até indispensável que ele o exerça. O que não é aceitável é ver-se uma contradição entre a liberdade de iniciativa e a justiça social a ponto de se afirmar que esta última só é atingível na medida em que se negue a primeira.

No entanto, deve ter prevalência a trajetória de concretização dos direitos fundamentais dos trabalhadores apesar das duras e cruéis imposições do neoliberalismo e do mercado global ${ }^{9}$.

${ }^{8}$ Cumpre mencionar a doutrina de Josué Lafayete Petter (2005, p. 161), ao destacar que se verifica, no mercado, em muitos segmentos, "a ocorrência do fenômeno de concentração do poder econômico, que fica, por assim dizer, assenhorado nas mãos de uns poucos, com ofensa à liberdade de iniciativa, invocando a necessidade de tutela e intervenção do Estado, pena de aquela literalmente sucumbir. Então, ao contrário do que se poderia imaginar, a intervenção do Estado no domínio econômico (CF, art. 174), muito antes de limitar a iniciativa e a liberdade do particular, tem por fim, mesmo, preservá-la."

9 Segundo Naomi Klein (2008, p. 4), ao tratar do pacote de U\$700 bilhões de ajuda do governo americano ao mercado financeiro, diante da atual e forte crise financeira, 
Resulta disso tudo ser imperioso fazer valer os princípios e regras fundamentais da Constituição Federal, em sintonia com as Normas Internacionais de Proteção dos Direitos Humanos que resguardam a dignidade da pessoa humana. Cumpre proclamar e exigir a observância do bem jurídico trabalho como valor social, um dos fundamentos do Estado Democrático do Direito (art. 1ํ, IV), eis que a ordem econômica deve ser fundada na valorização do trabalho (art. 170).

Com efeito, sob o manto do Estado Democrático de Direito, onde a Constituição Federal não só sobreleva a eminência da dignidade da pessoa humana, mas a transforma em valor fundante da ordem jurídica, como enfatiza José Afonso da Silva (1998, p. 91), todo trabalhador deve ser visto como detentor de direitos fundamentais sociais, amparado por normas pétreas da Constituição, que não podem ser afastadas nem eliminadas sequer por Emenda Constitucional, em face do implícito princípio constitucional que veda o retrocesso social. Para tanto, é preciso conciliar os valores sociais do trabalho e da livre iniciativa num ambiente de efetiva concretização do princípio da dignidade humana, mediante a fiel observância da função social da empresa, definida no art. 170, da Lei Maior.

Destarte, se, do ponto de vista econômico, as mudanças impostas pelas leis do mercado, no campo das relações entre o capital e o trabalho, visando à manutenção da empresa e do emprego, são inevitáveis, urge que seja preservada a pessoa humana, como tarefa inafastável do Estado Democrático de Direito. Como preleciona Sergio Alves Gomes (2008, p. 445-6),

respeitar a Constituição não significa apenas deixar de fazer o que ela proíbe, mas também e, sobretudo, fazer o que ela determina. Isso porque o referido paradigma estatal tem por escopo principal a transformação de uma sociedade injusta, egoísta, de raízes escravagistas e subdesenvolvida para uma sociedade livre, justa e solidária. A Constituição Federal de 1988, ao instituir o Estado Democrático de Direito, documenta um pacto comprometido com tal transformação. Um pacto que decidiu pelo desenvolvimento nacional, pela erradicação da pobreza e da marginalização, isto é, da exclusão social, bem como pela contínua redução das desigualdades sociais e regionais, a fim de 'promover o bem de todos' (CF, art. 3으. I e IV). Resta claro que quem - por ação ou omissão - colocar-se contra estes objetivos transformadores inscritos na Carta Magna da República põese, conseqüentemente, a favor da manutenção do subdesenvolvimento e do retrocesso democrático".

considerada a maior desde o crack da Bolsa de Nova York, em 1929, "a ideologia do livre mercado sempre esteve a serviço dos interesses do capital, e sua presença avança e recua, dependendo da utilidade que tem para esses interesses. Em épocas de crescimento, pregar o 'laissez faire' é rentável, porque o governo ausente permite o crescimento de bolhas especulativas. Quando essas bolhas estouram, a ideologia se torna um empecilho e entra em estado dormente, enquanto o grande governo parte em missão de salvamento". 
Como se vive em uma sociedade de trabalho, forçoso é valorizar sobremaneira o trabalho humano. A redução da taxa do desemprego estrutural depende basicamente do desenvolvimento do país, lastreado na educação e na justa distribuição da riqueza, na diminuição da taxa de juros e numa autêntica reforma fiscal, em consonância com a qualificação da mão-de-obra, conscientização e aperfeiçoamento das lideranças sindicais. Nessa esteira, incumbe aos órgãos governamentais, com a cooperação de grupos representativos da sociedade civil, principalmente dos grupos empresariais de grande porte, nacionais e transnacionais, desenvolver políticas públicas de forma a propiciar o crescimento do País nos seus diversos setores. Tudo de modo a facilitar o permanente acesso à qualificação da mão-de-obra e à capacitação profissional dos trabalhadores, mormente diante das inovações tecnológicas, como meios inexoráveis de se combater o desemprego. Só assim será possível assegurar igual liberdade de chances e oportunidades para todos.

Nessa senda, exsurge a relevância do papel da empresa, perante seus empregados e demais prestadores de serviços, por ser o espaço propício para todo trabalhador exercer permanentemente sua cidadania com liberdade e responsabilidade, em prol de seus interesses e de toda comunidade, onde a mesma está inserida. Segundo Josué Lafayete Petter (2005, p. 154),

valorizar o trabalho humano diz respeito a todas as situações em que haja mais trabalho, entenda-se, mais postos de trabalho, mais oferta de trabalho, mas também àquelas situações em que haja melhor trabalho, nesta expressão se acomodam todas as alterações fáticas que repercutem positivamente na própria pessoa do trabalhador (... o trabalho exercido com mais satisfação, com menos riscos, com mais criatividade, com mais liberdade, etc).

É desse modo que transparece com nitidez o caráter institucional da empresa como comunidade capaz de realizar plenamente sua destinação econômica e social, porém de um modo mais humano e solidário, para produzir prosperidades sociais (CF, art. 1ㅜㅡㄹ incisos III e IV; art. 170). Nunca o contrário.

Por tudo isso, a resolução das dificuldades, no mundo do trabalho, não pode ser entregue ao livre jogo das forças de mercado. Há de ser objeto de intervenção consciente do Estado, no pleno exercício de sua soberania junto às empresas e grupos econômicos, os quais, mesmo sendo detentores de autonomia, devem agir, segundo a programação e tomada de providências ditadas pelos órgãos estatais em total sintonia com os princípios e regras constitucionais, a fim de que o crescimento econômico possa propiciar eficazmente o progresso social. Para tanto, são necessários grandes investimentos para a criação de novas tecnologias ${ }^{10}$, a melhoria considerável da capacitação científica do país e, ao 
mesmo tempo, da capacitação dos trabalhadores em geral, diante das exigências do mercado global extremamente competitivo a impor tais avanços. Com isso, certamente, haverá a diminuição do desemprego estrutural que ainda assola o país, sendo notório o déficit de trabalhadores qualificados ${ }^{11}$.

Além de ser facilitado o acesso ao trabalho, como direito social que é (CF, art. $\left.6^{\circ}\right)$, a salvaguarda da dignidade humana depende ainda da efetiva garantia de manutenção do emprego conquistado. Convém lembrar a respeito que a Constituição Federal vigente, em seu art. 7ํㅜ, inc. I, prevê a proteção da relação de emprego contra despedida arbitrária ou sem justa causa, nos termos de lei complementar que preverá indenização compensatória, dentre outros direitos. E, enquanto, perdura esse vazio normativo, o art. 10, I, do Ato das Disposições Constitucionais Transitórias, dispõe que essa proteção se limita ao aumento, por quatro vezes, da porcentagem prevista no art. $6^{\circ}$, caput e $\S 1^{\circ}$, da Lei n. 5107 , de 13 de setembro de 1966. É o que, lamentavelmente, está em vigor desde então, há duas décadas.

${ }^{10}$ É sabido que o Brasil é um dos países líderes em produção científica mas continua com atraso tecnológico imenso. "Preferiu comprar tecnologia e conhecimento do exterior a desenvolver aqui, nas palavras do físico Ennio Condotti, ex-presidente da SBPC. Em quase todos os segmentos não vê transformação do conhecimento em tecnologia. Hoje, o país é responsável por cerca de $2 \%$ da ciência mundial, ocupando o 15 lugar no ranking dos países por produtividade, segundo levantamento da CAPES, em termos quantitativos. Contudo, cai para o $20^{\circ}$ lugar, em termos qualitativos. Para Miguel Nicolelis, cientista paulistano, líder de um laboratório na Universidade Duke, "é preciso mudar o paradigma de que ciência tem de ser feita só na universidade. Ela pode ser feita na indústria. $\mathrm{O}$ governo tem de começar a incentivar que as multinacionais façam centros de pesquisa aqui”. (Cf. Jornal Folha de São Paulo, Caderno MAIS, 28 de outubro de 2007, p. 4).

$\mathrm{Na}$ avaliação do geógrafo Carlos Walter Porto Gonçalves, Professor da Universidade Federal Fluminense, "os pesquisadores estariam mais interessados em patentear seus conhecimentos do que contribuir para a sociedade". Salienta como exemplo das dificuldades pelas quais passa o mundo científico, o fato de que os pesquisadores estão negligenciando informações sobre o impacto de suas pesquisas. Um desses casos seria o dos transgênicos. A universidade não diz se o transgênico é bom ou ruim porque as pesquisas são financiadas pelas empresas... Disse entender que a universidade passa por um processo de "privatização branca": os governos restringem o investimento nas instituições de ensino superior e empurram o financiamento da pesquisa para o setor privado. Essa política, disse ele, leva ao contexto em que a ciência deixa de funcionar 'no sentido da emancipação humana'. (Cf. Jornal de Londrina, 12 de novembro de 2007, p. 4).

${ }^{11}$ Tem sido divulgado, também, pelos meios de comunicação social que a oferta de trabalho está em desequilíbrio. Propala-se que não há mão de obra qualificada para 123 mil vagas com carteira assinada abertas pela indústria em 2007, de acordo com pesquisa realizada pelo Ipea (Instituto de Pesquisa Econômica Aplicada), órgão ligado ao Planejamento... A grande maioria - 7,5 milhões - tem baixa ou nenhuma 
Ora, a norma constitucional em vigor reconhece expressamente o direito do trabalhador de não ser despedido senão por justa causa ou motivo socialmente aceitável, coibindo a despedida arbitrária. Restou à Lei Complementar - que ainda não veio em face da total inércia do Poder Legislativo, no particular, durante esses últimos vinte anos - apenas fixar a indenização compensatória, dentre outros direitos, diante da afronta a tal imposição legal.

$\mathrm{Na}$ prática, contudo, é a dispensa sem justa causa que persiste. Ao empregado tem sido assegurado apenas o direito de receber a aludida indenização compensatória, além do aviso prévio e demais verbas rescisórias. No que se refere ao direito mais relevante, à manutenção do emprego, sua garantia permanece ao inteiro arbítrio do empregador, a quem cabe a decisão unilateral de manter, ou não, o trabalhador em seu quadro de pessoal.

Dessa injusta e cruel situação resulta a total insegurança ao trabalhador empregado, no seu dia a dia, diante da ameaça constante de dispensa sem qualquer justificativa plausível, o que reflete na organização de sua vida pessoal e familiar. Basta o querer da outra parte, para sujeitar o obreiro à brutal rotatividade do mercado de trabalho, cujas taxas, "nos últimos 10 anos se mantiveram acima de 40\%, praticamente em todo período. Em 2007, 14,3 milhões de trabalhadores foram admitidos e 12,7 milhões foram desligados das empresas. Do total de empregados de desligados, 59,4\%, ou 7,6 milhões foram dispensados por meio de demissões sem justa causa ou imotivadas"12. Trata-se, portanto, de verdadeira denúncia vazia, cláusula potestativa implícita no contrato individual de trabalho, malgrado o disposto no art. 122, do novo Código Civil, em vigor desde 11 de fevereiro de 2003, que a refuta por inteiro.

$\mathrm{O}$ direito a um posto de trabalho, bem como à manutenção do emprego, continua sendo relativizado, mesmo sendo este o principal meio de se assegurar o direito à vida com dignidade e o exercício da cidadania à população ativa, conforme já se destacou. Nesse contexto, a norma estatuída no mencionado art. $7^{\circ}$, inc. I, dotada de eficácia (CF, art. $\left.5^{\circ}, \S^{\circ} 1^{\circ}\right)$, deveria - e deve - ser interpretada em total sintonia com o disposto no arts. $1^{\circ}$, inc. III, e 170, da Lei Maior. Esta elegeu o princípio da dignidade da pessoa humana como fundamento da ordem constitucional e fim último da ordem econômica, de modo a compatibilizar os valores sociais do trabalho e da livre iniciativa numa estrutura empresarial

qualificação ou experiência profissional, sobretudo no Sudeste. (Cf. Jornal Folha de São Paulo, 8 de novembro de 2007, p. B1).

${ }^{12}$ Cf. Jornal da Associação dos Magistrados da Justiça do Trabalho da $3^{\underline{a}}$ Região, Ponto de Vista, abril/maio de 2008, p. 3. 
democrática (CF, art. IV). Resulta daí a total impossibilidade de exercício do direito potestativo pelo empregador, incrustado na cultura brasileira, ainda submetida aos reflexos de um sistema escravocrata que perdurou até 200 anos atrás.

Como bem evidencia Maurício Godinho Delgado (2004, p. 1115),

mesmo a leitura que defende a absoluta esterilidade da garantia de emprego mencionada no inciso I do art. 7o constitucional é, tecnicamente, passível de questionamento... A teoria constitucional moderna, mais bem ajustada à interpretação de novas constituições, tende a apreender, necessariamente, certa eficácia às normas constitucionais - ainda que diferenciada, em intensidade, a eficácia de uma e outra regra constitucional. Nessa linha, o preceito contido no inciso I do art. $7^{\circ} \mathrm{em}$ análise pode ser tido como regra de eficácia contida, produzindo, pelo menos, certo efeito jurídico básico, que seria o de invalidar dispensas baseadas no simples exercício potestativo da vontade empresarial, sem um mínimo de justificativa socioeconômica ou técnica ou até mesmo pessoal em face do trabalhador envolvido. ${ }^{13}$

Contudo, esse não é o entendimento dominante da doutrina e da jurisprudência trabalhista, que insiste em reconhecer a falta de eficácia e, por conseqüência, a não aplicação imediata da norma estatuída no inciso I, do art. 7º , da Constituição Federal, a qual exige uma motivação relevante para a dispensa do empregado.

A par disso, recentemente deixou de existir a possibilidade de nova ratificação da Convenção 158 da Organização Internacional do Trabalho (OIT) ${ }^{14}$. Isto porque, em 14.2.2008, o Presidente da República encaminhou mensagem (59/08) ao Congresso Nacional a propósito da ratificação dessa Convenção (CF, art. 84, inc. VIII). Porém, a Comissão de Relações Exteriores e de Defesa Nacional, no dia 2 de julho de 2008, rejeitou, por 20 votos a 1, a adesão do Brasil à aludida Convenção, por considerar a legislação brasileira suficiente para garantir direitos dos trabalhadores, reconhecendo ainda que a Convenção 158, "ao estabelecer uma complexa burocracia nos procedimentos sem justa causa, é inibidora da abertura de novas vagas" 15 .

${ }^{13} \mathrm{O}$ festejado autor define direito potestativo "como a prerrogativa assegurada pela ordem jurídica a seu titular de alcançar efeitos jurídicos de seu interesse mediante o exclusivo exercício de sua própria vontade. O poder, em suma, de influir sobre situações jurídicas de modo próprio, unilateral e automático”. (DELGADO, 2004, p. 649).

${ }^{14}$ Convém registrar que, nos termos do Decreto 1.855, de 10 de abril de 1996, foi promulgada a Convenção 158 da OIT, pelo Presidente da República, Fernando Henrique Cardoso, anteriormente submetida à aprovação do Congresso Nacional, por meio do Decreto Legislativo n. 68, de 16 de setembro de 1992. Posteriormente, através do Decreto 2.100, de 20 de dezembro de 1996, baixado pelo mesmo Presidente da República, tornou-se pública a denúncia, pelo Brasil, da Convenção 158 da OIT, que assim deixou de vigorar no Brasil, mesmo sob a égide da Constituição Federal de 1988. 
Ora, a Convenção 158, da OIT, não proíbe a dispensa do empregado, ou seja, não restaura a vetusta estabilidade geral. Apenas prevê que o empregador pode dispensar seu empregado desde que de forma justificada, diante de uma causa relacionada com sua capacidade ou seu comportamento e de relevantes motivos econômicos, tecnológicos, estruturais ou análogos, baseados no funcionamento da empresa, estabelecimento ou serviço. Para tanto, em se tratando de dispensas coletivas, reconhece ainda o direito à prévia informação e consulta aos representantes sindicais que atuam no âmbito da empresa, visando uma atuação conjunta a respeito dos critérios a serem estabelecidos. Em qualquer caso, impõe ao empregador a prova cabal da existência de uma causa justificada para qualquer dispensa de empregados.

Cumpre ressaltar que, sob o manto do Estado Democrático de Direito, a empresa, no pleno exercício de sua autonomia e função social, deve propiciar ao obreiro oportunidades de bem exercer sua cidadania de forma mais permanente, participando, em comunhão de esforços, para o aumento do produto social, ao ser integrado nessa estrutura. Com isso, criam-se vínculos de lealdade e de compromisso mútuos em busca de metas direcionadas à satisfação de interesses próprios, tanto do empresário quanto dos empregados bem como da própria comunidade.

Já a alta rotatividade dominante afasta a possibilidade de formação desse espírito de parceria e gera total insegurança aos trabalhadores na condução de suas vidas e de suas respectivas famílias, eis que a continuidade de seus contratos de trabalhos permanece dependendo quase que exclusivamente da vontade do outro contratante, o empregador. Com isso, o trabalho humano se desvaloriza em manifesta afronta à dignidade de todo obreiro. Por outro lado, essa mesma rotatividade impossibilita, por parte dos trabalhadores a ela submetidos, a formação de liames de maior responsabilidade e de comprometimento com os objetivos empresariais, inclusive no sentido de melhor assegurar a continuidade da própria empresa.

Em face dessa nefasta realidade, urge bem interpretar os princípios e regras da Constituição Federal como um complexo normativo unitário, de modo

${ }^{15}$ Nas palavras do Relator Deputado Júlio Delgado, que, ao pedir o arquivamento da mensagem presidencial, salientou que a norma internacional é prejudicial aos trabalhadores e à economia. Foi rebatido pelo deputado Nilson Mourão (PT-AC), o único a votar a favor, que destacou a prevalência dos interesses dos empresários, sendo certo que o crescimento da economia garante a geração de empregos, diante da assertiva do Relator de que "o alto custo e a restrição de dispensas tendem a reduzir a rotatividade, mas vão inibir a geração de empregos". In: http//www.camara.gov.br. 
a salvaguardar as relações de emprego contra despedidas arbitrárias e sem justa causa. E, desse modo, forçoso é atribuir hierarquia e natureza material constitucional às normas das convenções internacionais que reconhecem e tutelam direitos humanos, dentre as quais a Convenção 158, da OIT, diante do que dispõe o $\S 2^{\circ}$ do art. 5ㅇ, em total sintonia com o art. 7을 inciso I, ambos da mesma Lei Maior, a qual proclama a dignidade da pessoa humana e os valores sociais do trabalho, dentre outros, como fundamentos do Estado Democrático de Direito.

\section{CONCLUSÕES}

A tutela do trabalho humano e a efetividade dos direitos sociais resguardam a própria democracia, o que impõe a justaposição de forças políticas manifestadas pela intervenção estatal na ordem econômica, no sentido de garantir o respeito à dignidade humana, sem o qual o Estado Democrático de Direito não se sustenta. Assim, sobreleva a transcendência do princípio fundamental da dignidade humana que supera qualquer outra elaboração legislativa, porque ocupa um lugar central no pensamento filosófico, político e jurídico como valor supremo da ordem constitucional.

Partindo destas premissas, a questão do desenvolvimento depende da tomada de sérias políticas públicas tendentes a estabelecer uma dinâmica de equilíbrio entre os objetivos de ordem capitalista, voltados ao crescimento econômico, e a atuação regulatória do Estado de agregar aliados para enfrentar os problemas sociais. Instrumentos legais não faltam à luz de uma Constituição Federal que legitimou o capitalismo, ao propiciar condições efetivas para a liberdade de iniciativa e à livre concorrência, orientadas, porém, ao alcance da justiça social.

No âmbito internacional, como se deu na chamada era dos anos de ouro, busca-se, também neste histórico ano de 2008, a forte e indispensável intervenção do Estado na coordenação da política econômica, principalmente por aqueles que pregavam de forma impositiva os postulados neoliberais da desregulamentação. Com isso, retoma-se, com vigor, a idéia de inter-relação dos planos econômicos e sociais direcionados ao desenvolvimento e ao progresso social. Isso pode significar a transformação em realidade dos anseios democráticos de se proporcionar a todos as mesmas oportunidades de melhores condições de vida. Para tanto, a atuação dos poderes governamentais, da administração pública, deve ser séria e transparente, afastada do câncer da corrupção.

Vale dizer, havendo vontade política, o Estado tem condições, sim, de dar prioridade à concretização de direitos fundamentais à educação de qualidade, à saúde, à moradia digna, como ponto de partida, com vista à inclusão social. 
É preciso investir em novas tecnologias, no solo brasileiro, para gerar novas demandas e decorrentes empregos. Nesse particular, ainda falta às empresas - mais ainda aos grandes conglomerados nacionais e transnacionais - o exercício de sua função social, valorizando o trabalho humano, tal como vem proclamado no art. 170, da Lei Maior. No entanto, o Estado, no exercício de sua soberania, tem instrumentos institucionais de vincular suas ações de impulsionar a democracia às potencialidades das empresas em face do mercado, para daí extrair os meios necessários de obter o crescimento econômico de forma justa e sustentável.

Nesse contexto, deve ser eficazmente garantido o emprego conquistado, como único meio de se assegurar vida digna à grande maioria da população ativa, nos termos dos artigos 70, inciso I, da Lei Maior, 122, do Cód. Civil, e à luz da Convenção 158, da OIT, sendo certo que sem trabalho humano não se pode pretender a prosperidade do sistema capitalista, principalmente sendo este social. Por tudo isso, a valorização do trabalho humano se impõe, pois "o homem elabora seu potencial criador através do trabalho. É uma experiência vital. Nela o homem encontra sua humanidade ao realizar tarefas essenciais à vida humana e essencialmente humanas. A criação se desdobra no trabalho porquanto este traz em si a necessidade que gera as possíveis soluções criativas" (OSTROWER, 1987, p. 31; grifo nosso).

Espera-se que esta conscientização seja mais eficazmente disseminada no seio da sociedade brasileira - democrática, pluralista e capitalista - em busca do crescimento econômico aliado à exigência ética de justiça social, sob a égide de uma Constituição Federal a estabelecer que a ordem econômica deve ser fundada na valorização do trabalho humano (art. 170). Sem isso, não há como se alcançar o progresso social da Nação. Portanto, impõe-se a ação conjunta do Estado e da sociedade, para fazer prevalecer o DIREITO e o respeito à pessoa humana em qualquer circunstância, principalmente no mundo do trabalho.

\section{REFERÊNCIAS}

ABBAGNANO, Nicola. Dicionário de filosofia. Tradução coordenada por Alfredo Bosi. São Paulo: Mestre Jou, 1962.

ANTUNES, Ricardo. Os sentidos do trabalho: ensaio sobre a afirmação e a negação do trabalho. São Paulo: Boitempo, 2005.

BONAVIDES, Paulo. Do Estado Liberal ao Estado Social. São Paulo: Malheiros, 2001.

CANOTILHO, José Joaquim Gomes. Direito Constitucional. 5. ed. Coimbra: Almedina, 1992. 
DELGADO, Maurício Godinho. Curso de Direito do Trabalho. São Paulo: LTr, 2004.

EMBAIXADA DA REPÚBLICA FEDERAL ALEMANHA. Lei Fundamental da República Federal da Alemanha. Com um ensaio e anotações de Nuno Rogeiro. Coimbra: Coimbra Editora, 1996.

GOMES, Sergio Alves. Hermenêutica Constitucional: um contributo à construção do Estado Democrático de Direito. Curitiba: Juruá, 2008.

HÄBERLE, Peter. A dignidade humana como fundamento da comunidade estatal. In: SARLET, Ingo Wolfgang (Org.). Dimensões da dignidade: ensaios de Filosofia do Direito e Direito Constitucional. Porto Alegre: Livraria do Advogado, 2005.

HERVADA, Javier. A Pessoa. In: . Lições propedêuticas de Filosofia do Direito. Trad. Elza Maria Gaspartotto. São Paulo: Martinsfontes, 2008.

HESSE, Konrad. A força normativa da Constituição. Trad. Gilmar Mendes. Porto Alegre: Sergio Fabris, 1991.

HOBSBAWM, Eric. Era dos Extremos: o breve século XX 1914-1991. Trad. Marcos Santarrita. 2. ed. Companhia das Letras, 2001.

KANT, Immanuel. Fundamentação da Metafísica dos Costumes. Segunda Seção. Textos Selecionados por Marilena Chaú, trad. Maria Bernkopf, Paulo Quintela. Rubens Rodrigues Torres Filho. São Paulo: Abril Cultural, 1980. (Coleção Os Pensadores).

OSTROWER, Fayga. Criatividade e processo de criação. Petrópolis: Vozes, 1987. PETTER, Josué Lafayete. Princípios constitucionais da ordem econômica: o significado e o alcance do art. 170 da Constituição Federal. São Paulo: Revista dos Tribunais, 2005.

PRONI, Marcelo Weishaupt. Economia e sociedade nos Anos de Ouro. In: Economia e Proteção Social: textos para estudo dirigido. DEDECCA, Cláudio Salvatori; PRONI, Marcelo Weishaupt (Org.). 'Campinas: Unicamp. IE/Brasília, DF: Ministério do Trabalho e Emprego; Unitrabalho, 2006.

RAMALHO, José Ricardo; SANTANA, Marco Aurélio. Trabalhadores, sindicatos e a nova questão social. In: (Org.). Além da fábrica. São Paulo: Boitempo, 2003.

REALE, Miguel. Introdução à Filosofia. São Paulo: Saraiva, 1988. 
SARLET, Ingo Wolfgang. Dignidade da pessoa humana e direitos fundamentais na Constituição Federal de 1988. Porto Alegre: Livraria do Advogado, 2001.

SCHWARTZMN, Simon. As causas da pobreza. Rio de Janeiro: FGV, 2004.

SILVA José Afonso da. A dignidade da pessoa humana como valor supremo da democracia. Revista de Direito Administrativo, v. 212, 1998.

TOLEDO, Gastão Alves de. O Direito Constitucional Econômico e sua Eficácia. Rio de Janeiro/São Paulo: Renovar, 2004.

Artigo recebido em 25/11/08 e aceito em 05/06/09 